\title{
Aplikasi Media Informasi Website Pengenalan Tempat Pariwisata Belitung
}

\author{
Fanny Fransisca \\ Fakultas Science and Technic \\ Universitas Buddhi Dharma \\ Jl. Imam Bonjol No.41, Tangerang, \\ Banten, Indonesia \\ steflovfan@gmail.com
}

\author{
Yo Ceng Giap \\ Fakultas Science and Technic \\ Universitas Buddhi Dharma \\ Jl. Imam Bonjol No.41, Tangerang, \\ Banten, Indonesia \\ cenggiap@gmail.com
}

\author{
Jimmy Arifin \\ Fakultas Science and Technic \\ Universitas Buddhi Dharma \\ Jl. Imam Bonjol No.41, Tangerang, \\ Banten, Indonesia \\ jimmyarifin01@gmail.com
}

\begin{abstract}
Abstrak- Pariwisata menjadi salah satu sektor yang berkembang sangat cepat, bahkan di beberapa negara pariwisata menjadi faktor pendukung utama dalam perekonomian suatu negara. Belitung merupakan bagian dari Provinsi Kepulauan Bangka Belitung yang memiliki potensi pariwisata yang cukup baik dengan segala sumber daya yang dimilikinya. Tapi karena belum banyak dikenal oleh masyarakat. Maka dibuatlah penelitian ini sehingga masyarakat mengetahui tempat - tempat pariwisata yang ada di Belitung, dengan membuat perancangan sistem, melakukan analisis, dan pengujian sistem serta implementasi pada sistem aplikasi perancangan aplikasi media informasi pengenalan tempat pariwisata di belitung berbasis web. Dalam pengembangan sistem perancangan aplikasi media informasi pengenalan tempat pariwisata di belitung berbasis web penulis menggunakan beberapa metode dalam penelitiannya yaitu metode analisis untuk merencanakan, menganalisis, mendesain, dan mengimplementasi rancangan sistem, metode perancangan untuk merancang spesifikasi file sistem serta input dan output layar, metode pengumpulan data yaitu studi kepustakaan dan kuisioner dari sistem yang dibuat. Hasil dari dibangunnya perancangan aplikasi media informasi pengenalan tempat pariwisata di Belitung berbasis web diharapkan dapat memberi manfaat dan informasi tentang tempat - tempat pariwisata yang ada di Belitung kepada masyarakat. Untuk menguji sistem yang telah dibuat maka penulis melakukan survei dalam bentuk kuisioner. Maka berdasarkan kuisioner yang telah dibagikan dan diisi oleh para pengguna, dapat simpulkan bahwa aplikasi media informasi pengenalan tempat pariwisata di Belitung ini bermanfaat bagi pengguna karena membantu pengguna untuk lebih mengenal tempat - tempat pariwisata yang ada di Belitung, baik yang mengetahui atau tidak mengetahui tentang tempat pariwisata di Belitung.
\end{abstract} Web

Kata Kunci-Media Informasi, Tempat, Pariwisata, Belitung,

\section{Pendahuluan}

Sektor pariwisata merupakan salah satu sektor strategis dalam pengembangan perekonomian nasional maupun daerah. Sektor pariwisata di Indonesia didukung oleh letak strategis wilayah kita yang memiliki iklim tropis dan kekayaan alam yang sangat indah dan mempesona yang sayang apabila kita tidak kelola dan rawat dengan sebaik - baiknya, tempat pariwisata yang nyaman dan indah menimbulkan ketertarikan bagi wisatawan untuk berlibur dan menyaksikan keindahan alam tersebut.

Pada saat ini, banyak tempat pariwisata yang dapat kita jumpai baik di dalam kota maupun di luar kota. Salah satu tempat pariwisata yang masih menjaga dan menjunjung tinggi nilai kebudayaan adalah di Belitung, sehingga menarik perhatian turis - turis baik dari dalam (Domestic) maupun dari luar negeri (Internasional). Belitung juga memiliki keindahan alam yang sangat memukau, pantai yang indah dengan batu batu besar sehingga turis - turis suka berkunjung untuk menikmati liburannya atau menyaksikan pemandangan sunset yang menawan, dan masih banyak tempat - tempat wisata lainnya yang sayang apabila kita tidak kunjungi.

\section{Metodologi}

\section{A. Analisa Penelitian}

\section{Planning}

Pada tahap ini, memahami permasalahan yang muncul dan mendefinisikan secara rinci, kemudian menentukan tujuan dari pembuatan aplikasi serta mengidentifikasi segala kendala yang akan dihadapi.

\section{Analisa}

Merupakan kegiatan menganalisa system yang berjalan, dengan tahapan:

a. Mendefinisikan kebutuhan informasi, dan

b. Mendefinisikan kriteria performansi system.

\section{Desain Aplikasi}

Menentukan kebutuhan proses dan data pada aplikasi baru yang akan dirancang, langkah - langkahnya sebagai berikut:

a. Menyiapkan rancangan aplikasi secara detail.

b. Mengidentifikasi alternatif konfigurasi aplikasi.

c. Mengevaluasi alternatif konfigurasi aplikasi. 


\section{Implementasi}

Merupakan suatu kegiatan dalam mengimplementasikan rancangan yang telah disusun agar dapat diwujudkan, dengan langkah - langkah sebagai berikut berikut:
a. Merencanakan implementasi
b. Memberitahukan adanya implementasi
c. Menyediakan resource hardware dan software
d. Menyediakan database
e. Menyiapkan berbagai fasilitas fisik

\section{B. Metode Pengumpulan Data}

\section{Observasi}

Pengumpulan data dan informasi yang diperlukan untuk digunakan dalam pembuatan website media informasi untuk mengetahui beragam makanan khas di Pulau Jawa.

\section{Studi Pustaka}

Dalam penelitian ini penulis melakukan pengumpulan data-data yang sangat bermanfaat dari buku yang berhubungan dengan penelitian.

\section{Kuesioner}

Dalam penelitian ini, metode yang digunakan untuk memperoleh informasi dari responden adalah kuesioner. Jenis kuesioner ini adalah kuesioner tertutup yang disediakan jawabannya sehingga responden hanya perlu memilih jawaban pada kolom yang sudah disediakan dengan memberikan tanda centang $(\sqrt{ })$.

\section{Perancangan Sistem}

\section{A. Analisa Kebutuhan Sistem}

Dari hasil survei kepada tiga orang Bangka Belitung, peneliti kemudian membuat serta merancang aplikasi namun tidak semua kebutuhan pengguna dapat dipenuhi, berikut adalah rincian kebutuhan pengguna yang terdapat dalam aplikasi:

Tabel 1 Tabel Analisa Kebutuhan Pemakai

\begin{tabular}{|c|c|c|}
\hline No. & Kebutuhan Pemakai & Keterangan \\
\hline 1 & Ada foto tempat wisatanya & $\checkmark$ \\
\hline 2 & Dapat memuat komentar pengguna & $\mathbf{x}$ \\
\hline 3 & Dapat memberi emoticon saat komentar & $\checkmark$ \\
\hline 4 & Memberi data dan informasi yang jelas & $\mathbf{x}$ \\
\hline 5 & Ada video tempat wisatanya & $\mathbf{x}$ \\
\hline 6 & $\begin{array}{c}\text { Memberikan rekomendasi tempat } \\
\text { penginapan terbaik saat berwisata di } \\
\end{array}$ & $\checkmark$ \\
\hline 7 & Tamplitung web yang menarik & $\checkmark$ \\
\hline 8 & Mudah digunakan oleh user & $\mathbf{x}$ \\
\hline 9 & Memuat informasi yang lengkap & $\checkmark$ \\
\hline 10 & Terdapat rekomendasi utama pariwisata & $\checkmark$ \\
\hline 11 & Fasilitas transportasi yang tersedia & \\
\hline 12 & Biaya penginapan yang diperlukan & \\
\hline
\end{tabular}

\section{B. Perancangan User Interface}

Perancangan dari sistem berdasarkan tema penelitian ini menghasilkan beberapa halaman yang serupa dengan berisikan materi yang berbeda antara satu pembahasan dengan pembahasan lainnya. Adapun tampilan - tampilan program adalah sebagai berikut:

1. Halaman Beranda

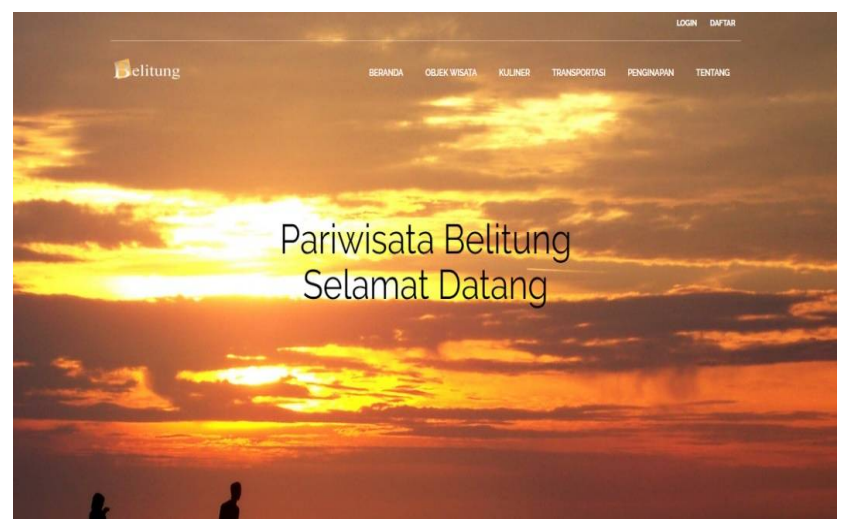

Gambar 1. Halaman Beranda

Pada halaman ini terdapat beberapa menu yaitu menu login, daftar, objek wisata, kuliner, transportasi, penginapan, dan tentang yang mewakili fungsi masing-masing menu.

\section{Halaman Login}

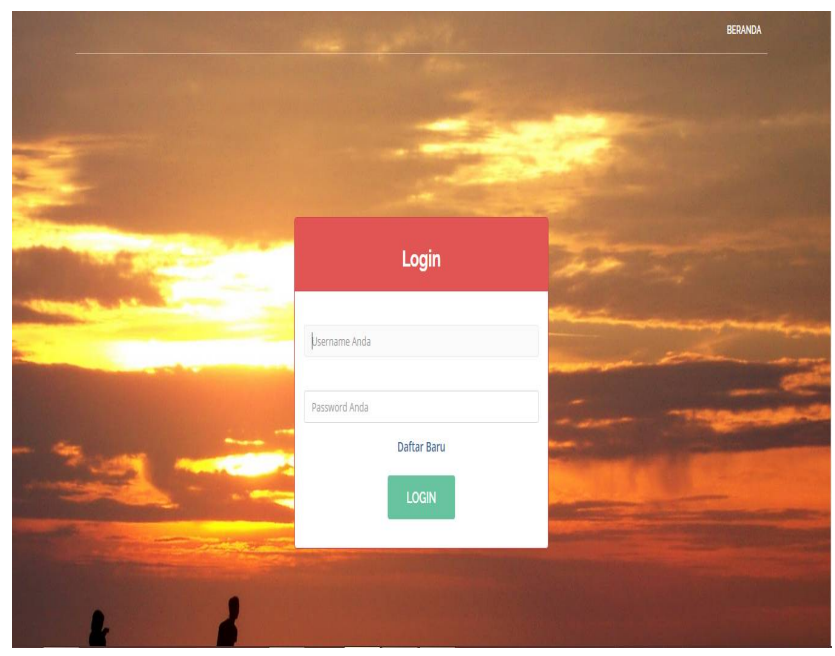

Gambar 2. Halaman Login

Pada halaman ini pengguna bisa login dengan memasukkan username, password yang benar, dan pada halaman ini terdapat tombol beranda, daftar baru dan login.

3. Halaman Daftar Baru 


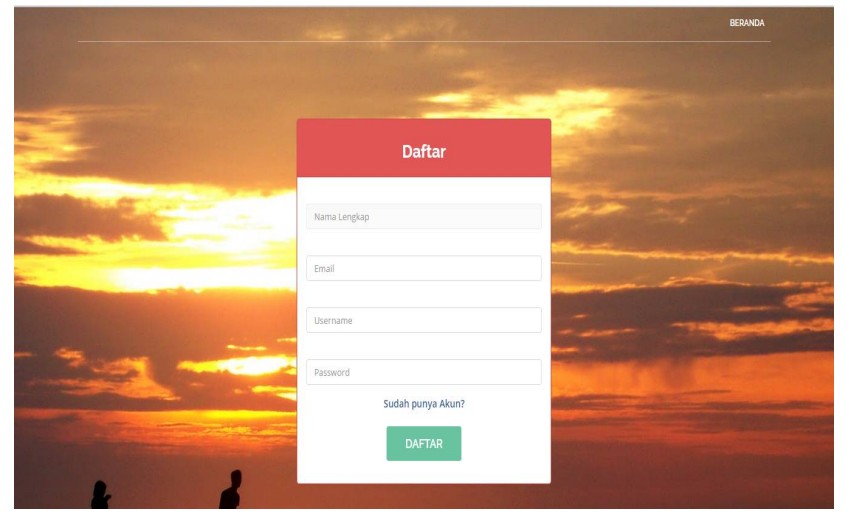

Gambar 3. Halaman Daftar Baru

Pada halaman ini pengguna bisa membuat akun baru dengan cara mengisi form daftar yang berisi nama lengkap, email, username, password. Dan terdapat tombol beranda, dan daftar.

\section{Halaman Objek Wisata}

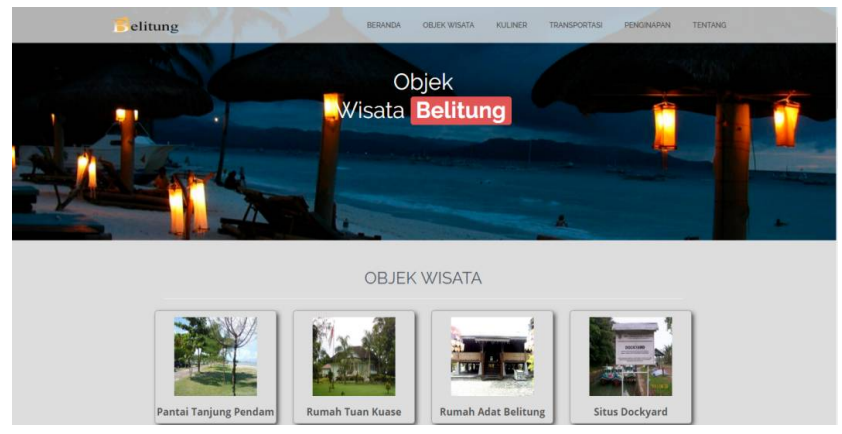

Gambar 4. Halaman Objek Wisata

Pada halaman ini terdapat daftar objek wisata yang ada di Belitung. Dan disertai tombol menu beranda, kuliner, transportasi, penginapan, tentang, dan logout.

\section{Halaman Rincian Objek Wisata}

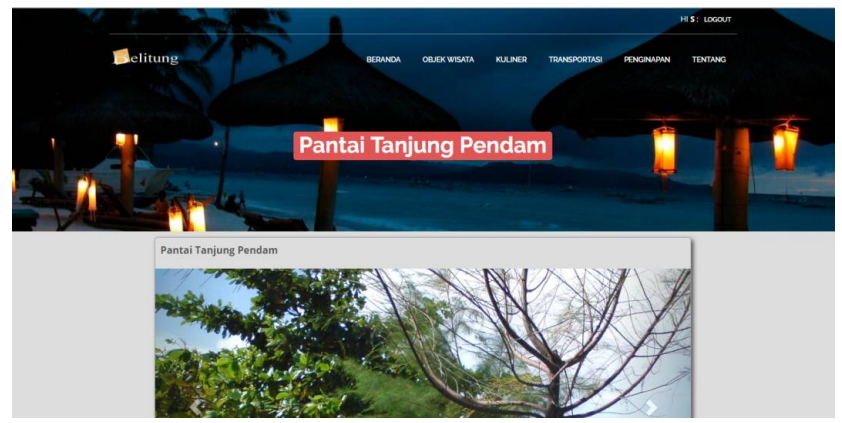

Gambar 5. Halaman Rincian Objek Wisata

Halaman ini akan menampilkan informasi beserta foto dari objek wisata yang telah dipilih dan juga tersedia kolom komentar. Dan disertai tombol menu beranda, objek wisata, kuliner, transportasi, penginapan, tentang, dan logout.

\section{Halaman Kuliner}

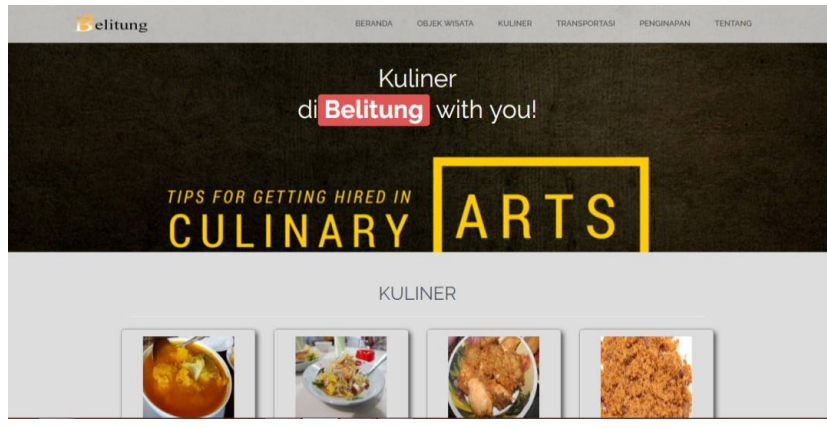

Gambar 6. Halaman Kuliner

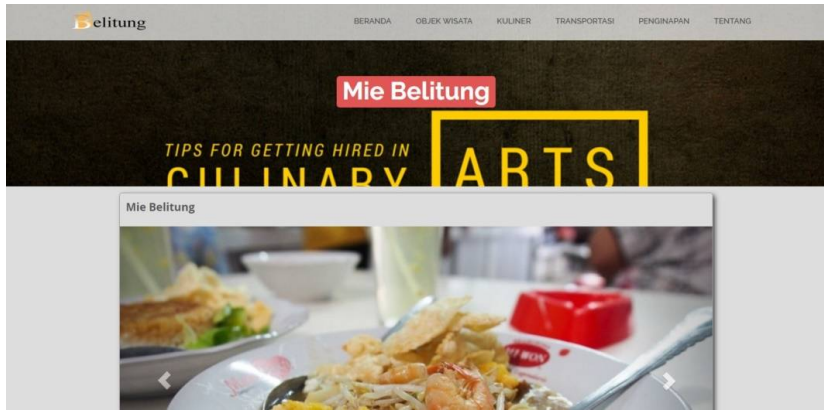

Gambar 7. Halaman Rincian Kuliner

Halaman ini akan menampilkan informasi beserta foto dari kuliner yang telah dipilih dan juga tersedia kolom komentar. Dan disertai tombol menu beranda, objek wisata, kuliner, transportasi, penginapan, tentang, dan logout.

\section{Halaman Transportasi}

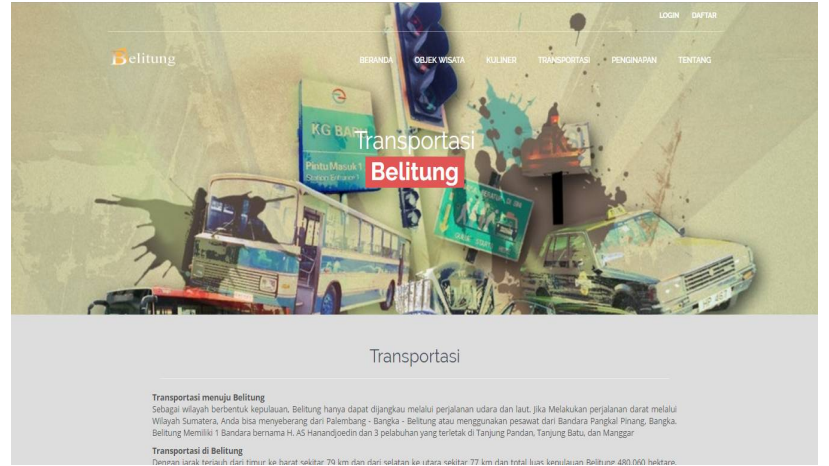

Gambar 8. Halaman Transportasi

Pada halaman ini terdapat informasi tentang transportasi di Belitung, jarak tempuh antar kota, dan juga informasi agen travel seperti alamat, no telepon, website, dan email. Dan 
disertai tombol menu beranda, objek wisata, kuliner, penginapan, tentang, dan logout.

8. Halaman Penginapan

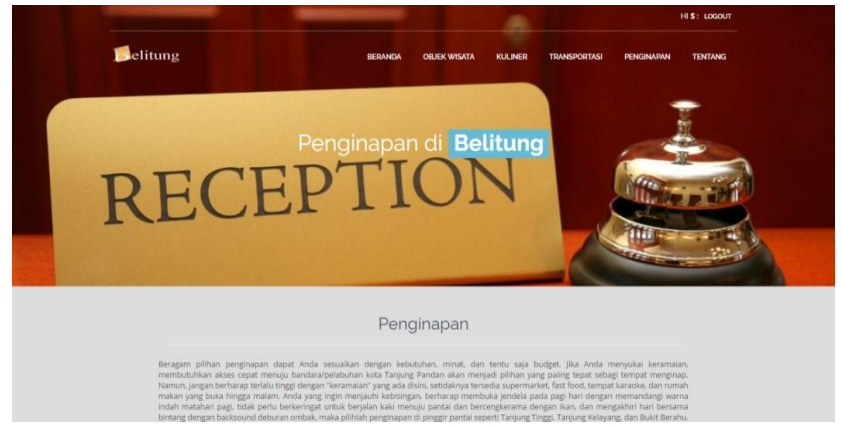

Gambar 9. Halaman Penginapan

Pada halaman ini terdapat informasi tentang penginapan/hotel di Belitung, di kelompokkan berdasarkan kecamatan, beserta kisaran harganya. Dan disertai tombol menu beranda, objek wisata, kuliner, transportasi, tentang, dan logout.

\section{Halaman Tentang}

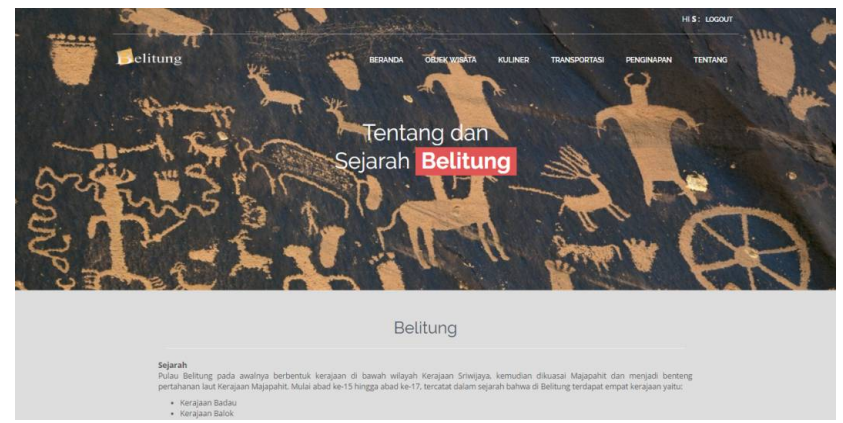

Gambar 10. Halaman Tentang

Pada halaman ini berisi informasi tentang dan sejarah Pulau Belitung, dan disertai dengan menu lainnya.

\section{PEMBAHASAN}

\section{A. Pengujian Whitebox}

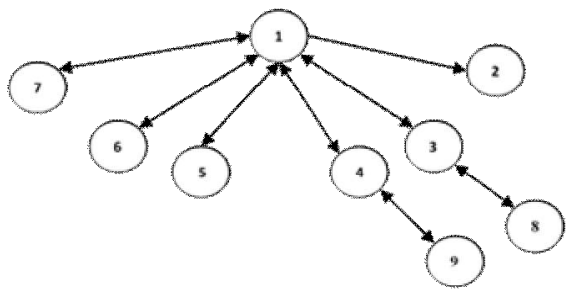

Gambar 11. Diagram Alir Aplikasi

Path yang dapat dibentuk sebagai berikut:

$$
\begin{array}{ll}
\text { 1. } & 1-2 \\
\text { 2. } & 1-3-1-2 \\
\text { 3. } & 1-3-8-3-1-2 \\
\text { 4. } & 1-4-1-2 \\
\text { 5. } & 1-4-9-4-1-2 \\
\text { 6. } & 1-5-1-2 \\
\text { 7. } & 1-6-1-2 \\
\text { 8. } & 1-7-1-2
\end{array}
$$

Region yang dapat dibentuk sebanyak delapan (8), selanjutnya akan di uji dengan menggunakan rumus Cyclomatic Complexcity.

$$
\begin{aligned}
\mathrm{V}(\mathrm{G}) & =\mathrm{E}-\mathrm{N}+2 \\
& =15-9+2 \\
& =8
\end{aligned}
$$

Dari region yang didapat menggunakan diagram alir dan rumus menunjukan jumlah yang sama, yang artinya sistem sudah berjalan dengan benar. Selanjutnya akan diteruskan dengan pengujian blackbox.

\section{B. Pengujian Blackbox}

Pengujian black box akan menguji apakah tombol-tombol pada tiap Scene bekerja dengan baik atau tidak. Berikut hasil pengujian setiap tombol pada tiap Scene.

Tabel 2. Pengujian Blackbox

\begin{tabular}{|l|l|l|l|}
\hline $\begin{array}{l}\text { Uji Coba } \\
\text { / Scene }\end{array}$ & Uraian & Hasil yang diharapkan & $\begin{array}{l}\text { Hasil } \\
\text { sebenarnya }\end{array}$ \\
\hline 1 & Tombol Beranda & $\begin{array}{l}\text { Menampilkan halaman beranda dan memunculkan 7 tombol yaitu login, daftar, } \\
\text { objek wisata, kuliner, transportasi, penginapan, dan tentang }\end{array}$ & Sesuai \\
\hline 2 & Tombol Login & Masuk ke halaman login & Sesuai \\
\hline 3 & Tombol Daftar & Masuk ke halaman form daftar & Sesuai \\
\hline 4 & Tombol Objek Wisata & $\begin{array}{l}\text { Masuk ke halaman objek wisata yang menampilkan objek - objek wisata yang ada } \\
\text { di Belitung }\end{array}$ & Sesuai \\
\hline
\end{tabular}




\begin{tabular}{|l|l|l|l|}
\hline 5 & Menu Kuliner & $\begin{array}{l}\text { Masuk ke halaman kuliner yang menampilkan kuliner - kuliner yang ada di } \\
\text { Belitung }\end{array}$ & Sesuai \\
\hline 6 & Menu Transportasi & $\begin{array}{l}\text { Masuk ke halaman transportasi yang memberikan informasi tentang transportasi } \\
\text { yang ada di Belitung }\end{array}$ & Sesuai \\
\hline 7 & Menu Penginapan & $\begin{array}{l}\text { Muncul halaman penginapan yang memberikan informasi tentang penginapan di } \\
\text { setiap kecamatan yang ada di Belitung, seperti Tanjung Pandan, Sijuk, } \\
\text { Membalong, Selat Nasik, Kelapa Kampit, Gantung, Simpang Pesak dan Manggar }\end{array}$ & Sesuai \\
\hline 8 & Tombol Tentang & Muncul halaman tentang yang memberikan informasi tentang Belitung & Sesuai \\
\hline 10 & Menu Rincian Objek & $\begin{array}{l}\text { Masuk ke halaman rincian objek wisata yang telah dipilih dan memberikan } \\
\text { informasi tentang objek wisata tersebut disertai fotonya }\end{array}$ & Sesuai \\
\hline
\end{tabular}

\section{Hasil Pengolahan Kuesioner}

Tabel 3. Tabel Hasil Kuesioner Secara Keseluruhan

\begin{tabular}{|c|c|c|c|c|c|}
\hline \multirow{2}{*}{ No. } & & Ya & \multicolumn{3}{|l|}{ Tidak } \\
\cline { 3 - 6 } & Pertanyaan & Jumlah & $\%$ & Jumlah & $\%$ \\
\hline 1 & Pertanyaan 1 & 9 & $90 \%$ & 1 & $10 \%$ \\
\hline 2 & Pertanyaan 2 & 8 & $80 \%$ & 2 & $20 \%$ \\
\hline 3 & Pertanyaan 3 & 10 & $100 \%$ & 0 & 0 \\
\hline 4 & Pertanyaan 4 & 10 & $100 \%$ & 0 & 0 \\
\hline 5 & Pertanyaan 5 & 10 & $100 \%$ & 0 & 0 \\
\hline 6 & Pertanyaan 6 & 9 & $90 \%$ & 1 & $10 \%$ \\
\hline 7 & Pertanyaan 7 & 10 & $100 \%$ & 0 & 0 \\
\hline 8 & Pertanyaan 8 & 10 & $100 \%$ & 0 & 0 \\
\hline 9 & Pertanyaan 9 & 7 & $70 \%$ & 3 & $30 \%$ \\
\hline 10 & Pertanyaan 10 & 7 & $70 \%$ & 3 & $30 \%$ \\
\hline Total & & 90 & $90 \%$ & 10 & $10 \%$ \\
\hline
\end{tabular}

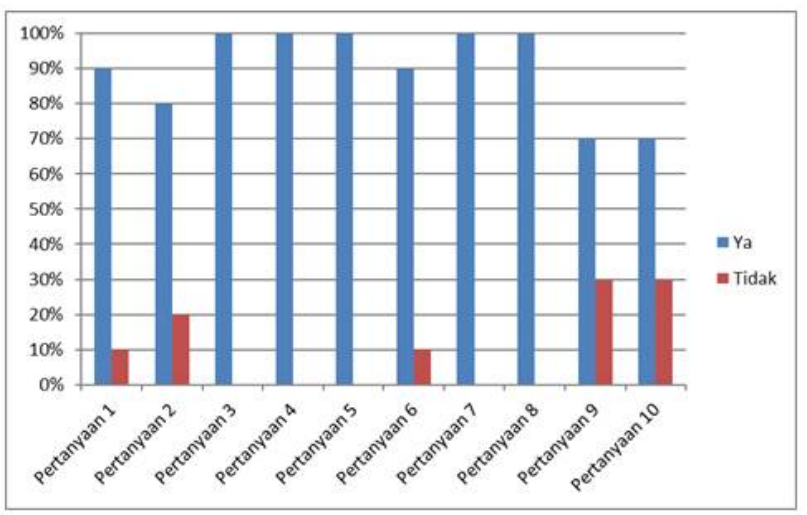

Gambar 12. Diagram Hasil Kuisioner Secara Keseluruhan

Setelah kuisioner dibagikan dan didapat hasil berupa data serta dianalisa maka dapat disimpulkan bahwa aplikasi ini adalah baik. Pengguna dapat mengerti cara penggunaan aplikasi serta memahami informasi yang diberikan karena dilengkapi contoh gambar yang bervariasi sehingga membantu pengguna mengenal objek pariwisata di Belitung.

\section{Penutup}

\section{A. Kesimpulan}

Berdasarkan uji coba dan evaluasi yang telah dilakukan maka dapat diambil kesimpulan sebagai berikut:

- Aplikasi pengenalan tempat wisata ini dapat membantu user yang belum mengenal pulau Belitung, penulis juga menambahkan pengenalan singkat tentang Belitung dan beberapa kuliner di Belitung.

- Aplikasi ini dapat membantu sekaligus memudahkan wisatawan domestik yang ingin liburan ke Belitung dengan memperkenalkan dan memberikan informasi di setiap wilayah.

- Aplikasi ini dapat menunjukkan foto berupa gambar objek wisata yang berada di Belitung.

\section{B. Saran}

Berdasarkan analisa yang telah dilakukan maka dapat diusulkan beberapa saran agar aplikasi media informasi ini lebih baik lagi, yaitu:

- Menambahkan musik dan video agar lebih menarik lagi.

- Menambahkan gambar foto yang lebih banyak beserta keterangan yang lebih lengkap lagi agar lebih menarik lagi.

- Lokasi objek wisata dapat dihubungkan dengan google map.

\section{DAFTAR PUSTAKA}

[1] Al Fatta, Hanif, 2007, Analisis dan Perancangan Sistem Informasi untuk Keunggulan Bersaing Perusahaan dan Organisasi Modern, Yogyakarta: Penerbit ANDI.

[2] Binanto, Iwan, 2010, Multimedia Digital - Dasar Teori dan Pengembangannya, Yogyakarta: Penerbit ANDI. 
[3] Maya Yulianingsih, Tri, 2010, Jelajah Wisata Nusantara, Yogyakarta.

[4] Nova, Firsan, 2009, Crisis Public Relations - Bagaimana PR Menangani Krisis Perusahaan, Jakarta: Penerbit Grasindo.

[5] Prabawi, Ari, TH, 2010, Pengembangan Aplikasi Database Berbasis JavaDB Dengan Netbeans, Yogyakarta: Andi Offset.

[6] Raharjo, Suwanto, 2008, Pemrograman Web Dinamis Menggunakan PHP, Yogyakarta
[7] Rainer, R.Kelly,\& Casey G. Cegielski, 2011, Introduction to Information Systems Enabling and Transforming Business, Penerbit John Wiley \& Sons, Inc.

[8] Ramadhan, Arief, 2006, Student Guide Series Pemrograman Web, Jakarta: PT Elex Media Komputindo.

[9] Santoso, Insap, 2009, Interaksi Manusia dan Komputer, Yogyakarta: Andi Offset. 